\title{
Expression of chemerin and its receptors in rat testes and its action on testosterone secretion
}

\author{
Lei $\mathrm{Li}^{1,{ }^{*}}$, Ping Ma ${ }^{1, *}$, Chen Huang ${ }^{1}$, Yongjun Liu', Ye Zhang ${ }^{1}$, Chen Gao', Tianxia Xiao', \\ Pei-Gen Ren', Brian A Zabel ${ }^{2}$ and Jian V Zhang ${ }^{1,3}$ \\ ${ }^{1}$ Laboratory for Reproductive Health, Shenzhen Institute of Advanced Technology, Chinese Academy of Sciences, \\ Shenzhen 518055, China \\ ${ }^{2}$ Palo Alto Institute for Research and Education, Veterans Affairs Palo Alto Health Care System, Palo Alto, \\ California 94304, USA \\ ${ }^{3}$ Guangdong Key Laboratory of Nanomedicine, Guangdong, China \\ *( L Li and P Ma contributed equally to this work)
}

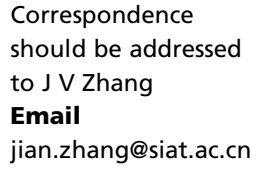

\begin{abstract}
The novel adipokine chemerin plays a role in the regulation of lipid and carbohydrate metabolism, and recent reports of elevated chemerin levels in polycystic ovarian syndrome and preeclampsia have pointed to an emerging role of chemerin in reproduction. We hypothesised that chemerin, like other adipokines, may function to regulate male gonadal steroidogenesis. In this study, we show that chemerin and its three receptors chemokine-like receptor 1 (CMKLR1), G-protein-coupled receptor 1 (GPR1) and chemokine (C-C motif) receptor-like 2 were expressed in male reproductive tracts, liver and white adipose tissue. CMKLR1 and GPR1 proteins were localised specifically in the Leydig cells of human and rat testes by immunohistochemistry. The expression of chemerin and its receptors in rat testes was developmentally regulated and highly expressed in Leydig cells. In vitro treatment with chemerin suppressed the human chorionic gonadotropin (hCG)induced testosterone production from primary Leydig cells, which was accompanied by the inhibition of 33-hydroxysteroid dehydrogenase gene and protein expression. The hCGactivated p44/42 MAPK (Erk1/2) pathway in Leydig cells was also inhibited by chemerin cotreatment. Together, these data suggest that chemerin is a novel regulator of male gonadal steroidogenesis.
\end{abstract}

\author{
Key Words \\ - chemerin \\ - steroidogenesis \\ - testosterone \\ - adipokine \\ - Leydig cell
}

\section{Introduction}

Chemerin, also known as retinoic acid receptor responder protein 2 (RARRES2), was initially identified as a chemoattractant ligand for the G protein-coupled receptor (GPR), chemokine-like receptor 1 (CMKLR1, also known as ChemR23 or DEZ) (Meder et al. 2003, Wittamer et al. 2003, Zabel et al. 2005b). It was subsequently identified as a novel adipokine that regulates adipogenesis and adipocyte metabolism, with high expression levels in white adipose tissue (Goralski et al. 2007). Chemerin is secreted as an $18-\mathrm{kDa}$ inactive precursor protein and undergoes extracellular serine protease cleavage of the C-terminus to generate the 16-kDa active form (Wittamer et al. 2003, Zabel et al. 2005a). Chemerin is expressed at relatively high levels not only in liver, white adipose tissue and placenta, but is also present in skin, adrenal gland, all parts of the gut, pancreas, the airways and the kidney 
(Wittamer et al. 2003, Goralski et al. 2007). Chemerin attracted great interest for its proposed roles in adaptive and innate immunity, inflammation, lipid and carbohydrate metabolism and its association with obesity and diabetes (Bondue et al. 2011). Elevated plasma chemerin levels are correlated with obesity and diabetes in both patients (Bozaoglu et al. 2007) and animal models (Ernst et al. 2010, Parlee et al. 2010).

To date, three receptors have been shown to bind chemerin: CMKLR1 (Meder et al. 2003, Wittamer et al. 2003, Zabel et al. 2005b), chemokine (C-C motif) receptor-like 2 (CCRL2; Zabel et al. 2008) and G protein-coupled receptor 1 (GPR1; Barnea et al. 2008); all of which are heptahelical receptors. Chemerin binding to CMKLR1 leads to internalisation of the chemerin-receptor complex and promotes leukocyte chemotaxis; chemerin binding to GPR1 stimulates receptor internalisation with no reported physiological roles (Barnea et al. 2008); chemerin binding to CCRL2 does not stimulate internalisation or chemotaxis, but might present chemerin to nearby cell displaying functional receptors (Monnier et al. 2012). The activation of chemerin/CMKLR1 resulted in intracellular calcium release, inhibition of cAMP accumulation and phosphorylation of MAPK ERK1/2 or the phosphatidylinositol 3-kinase/Akt pathway (Yoshimura \& Oppenheim 2011).

The critical roles played by adipokines in fertility and reproduction have been recently reviewed (Hausman \& Barb 2010, Poulos et al. 2010, Tersigni et al. 2011). For example, leptin antagonised the augmenting effect of several growth factors (insulin-like growth factor 1 (IGF1) and transforming growth factor) and hormones (insulin and glucocorticoids) on gonadotropin-stimulated steroidogenesis in both follicular and theca ovarian cells throughout the menstrual cycle (Spicer \& Francisco 1998, Agarwal et al. 1999, Barkan et al. 1999, Brannian et al. 1999, Kitawaki et al. 1999, Zachow et al. 1999). Though most of the published research focused on the relevance of adipokines in female fertility and reproduction, several studies described the important roles of adipokines in testicular steroidogenesis as well. Leptin and adiponectin were both found to inhibit basal and human chorionic gonadotropin (hCG)-induced testosterone production in rat testis, while resistin-stimulated testosterone production in rat testis (Tena-Sempere et al. 1999, Nogueiras et al. 2004).

Recent reports point to a role of the novel adipokine chemerin in reproduction as well, focusing on female reproductive disorders. Polycystic ovary syndrome patients have elevated circulating and adipose tissue chemerin levels (Tan et al. 2009), preeclampsia patients have elevated circulating chemerin levels (Duan et al. 2011, Stepan et al. 2011) and foetuses of obese mothers have increased chemerin concentrations, which correlates with maternal insulin sensitivity (Barker et al. 2012). Moreover, chemerin level has been quantified in rat placenta which has been found to be higher than in the liver (Garces et al. 2012). Expression of chemerin and its receptor CMKLR1 was reported in human granulosa cell, and chemerin treatment inhibited IGF1-induced progesterone and oestradiol $\left(\mathrm{E}_{2}\right)$ secretion (Reverchon et al. 2012). A similar suppressive effect of chemerin on FSHstimulated progesterone and $\mathrm{E}_{2}$ secretion was reported in rat granulosa cells (Wang et al. 2012). Although chemerin and its receptors are expressed in human and mouse testes (Wittamer et al. 2003, Takahashi et al. 2011), their biological actions in the male gonad remains unexplored. In this study, we characterised the cellular expression of chemerin and its receptors in rat testes and show that chemerin functions to suppress testicular steroidogenesis.

\section{Materials and methods}

\section{Human sample and animals}

Normal human testis paraffin sections were purchased from Pantomics, Inc. (San Francisco, CA, USA). SpragueDawley rats (postnatal 5-, 15-, 30-, 60- and 90-day-old) were obtained from the Laboratory Animal Center, Institutes of Biomedicine and Health, Chinese Academy of Sciences. All procedures related to animal usage were approved by the Committee on the Use of Live Animals for Teaching and Research, Shenzhen Institutes of Advanced Technology, Chinese Academy of Sciences.

\section{RNA analysis by QPCR}

Total RNA from the tissues and cells was extracted using TRIzol Reagent (Invitrogen) and subjected to QPCR analysis. RNA samples $(1 \mu \mathrm{g})$ were reverse transcribed into cDNA according to the manufacturer's instructions (Bio-Rad Laboratories). The PCR mixtures contained $10 \mu \mathrm{l}$ SYBR Premix Ex Taq II (Takara, Shiga, Japan), $500 \mathrm{nM}$ of each primer, $1 \mu \mathrm{l}$ template cDNA and DNase-free water to a final volume of $20 \mu \mathrm{l}$. Cycle conditions were $95^{\circ} \mathrm{C}$ for $10 \mathrm{~s}$, followed by 45 cycles of $95^{\circ} \mathrm{C}$ for $5 \mathrm{~s}, 60^{\circ} \mathrm{C}$ for $30 \mathrm{~s}$ and $72^{\circ} \mathrm{C}$ for $30 \mathrm{~s}$. The reaction was completed with a dissociation step for melting point analysis from 50 to $95^{\circ} \mathrm{C}$ (in increments of $0.5^{\circ} \mathrm{C}$ for $10 \mathrm{~s}$ each). The primers were designed on the basis of the published sequences of chemerin (forward, TGTGCAGTGGGCCTTCCA; reverse, CAAAGGTGCCAG

Published by Bioscientifica Ltd 
CTGAGAAGA), Cmklr1 (forward, CAAGCAAACAGCCACTACCA; reverse, TAGATGCCGGAGTCGTTGTAA), Gpr1 (forward, GGAGCTCAGC ATTCATCACA; reverse, GACAGGCTCTTGGTTTCAGC), Ccrl2 (forward, CTCTGCTTGTCCTCGTGCTT; reverse, GCCCACTGTTGTCCAGGTAG), and steroidogenic acute regulatory protein (Star; forward, CTGCTA GACCAGCCCATGGAC; reverse, TGATTTCCTTGACATTTGGGTTCC), cytochrome P450 cholesterol side-chain cleavage (Cyp11a1; forward, CTATGCCATGGGTCGAGAAT; reverse, CAGCACGTTGATGAGGAAGA), 3ß-hydroxysteroid dehydrogenase ( $H s d 3 b$; forward, AGCAAAA AGATGGCCGAGAA; reverse, GGCACAAGTATGCAATGTGCC) and Hsd17b1 (forward, AATGTGCTTTC CATTTGCAAGGT; reverse, ATGCCACTGGCAGAGGAGATG), $\beta$-actin (forward, GGAAATCG TGCGTGACATTA; reverse, AGGAAGGAAG GCTGGAAGAG) and ribosomal protein L19 (Rpl19; forward, ATCGCCAA TGCCAACTCC; reverse, TCATC CTTCT CATCCAGGTCA). The relative gene expression was normalised to Rpl19 in the developmental study and to $\beta$-actin in the comparison between the whole testis and the Leydig cells of the 3-month-old rats. The RNA levels were calculated using the $\Delta \Delta C T$ method, where $C T$ was the cycle threshold (Livak \& Schmittgen 2001). Melt curve analysis for each primer set revealed only one peak for each product. The size of the PCR products was confirmed by comparing the size with a commercial ladder after agarose gel electrophoresis.

\section{Immunohistochemistry}

The testes were dissected from 3-month-old SpragueDawley rats after decapitation and then, fixed, processed for embedding in paraffin and sectioned. Normal human testis paraffin sections were purchased from Pantomics, Inc. Immunohistochemistry was carried out on $5 \mu \mathrm{m}$ sections of paraffin-embedded tissues with a Peroxidaselabelling Kit (Vector Laboratories, Burlingame, CA, USA). The antibodies used for the immunohistochemistry were mouse MAB to GPR1 (clone 043, gift from Drs B Zabel and E Butcher, Stanford University, USA), mouse polyclonal antibody to CCRL2 (ab88632, Abcam, Cambridge, MA, USA), goat polyclonal antibody to GPR1, goat polyclonal antibody to ChemR23 (CMKLR1), goat polyclonal antibody to chemerin (sc-48179, sc-32651, sc-47479 all from Santa Cruz). Staining was visualised using a DAB Substrate Kit for peroxidase (Vector Laboratories), counterstained with haematoxylin. The primary antibody was replaced with IgG from control sections to check for non-specific staining.

\section{Primary Leydig cell culture}

Leydig cells were isolated from the testes of 3-month-old sexually mature Sprague-Dawley male rats as described previously with some modifications (Li \& Wong 2008). The testes from five rats were excised rapidly after decapitation and washed twice in $1 \times$ PBS. The decapsulated testes were digested for $15 \mathrm{~min}$ by shaking at 80 cycles $/ \mathrm{min}$ at $34^{\circ} \mathrm{C}$ in DMEM/F12 Ham (1:1) (Gibco-BRL) containing 0.1\% BSA and supplemented with $0.5 \mathrm{mg} / \mathrm{ml}$ collagenase type IA, $0.25 \mathrm{mg} / \mathrm{ml}$ soybean trypsin inhibitor (all from Sigma). To stop the digestion, ice-cold medium was added to the flask and the suspension was allowed to settle for $5 \mathrm{~min}$. Then the supernatant containing Leydig cells was filtered through cell strainers $(70 \mu \mathrm{m}$ nylon, Falcon BD Biosciences, Franklin Lakes, NJ, USA). The tubules were dispersed in another $50 \mathrm{ml}$ medium, and the supernatant was pooled and centrifuged. Discontinuous Percoll (Amersham Biosciences) gradients (with six density fractions ranging from 1.030 to $1.096 \mathrm{~g} / \mathrm{ml}$ ) were used to separate the Leydig cells. The Leydig cells located at the boundary between fractions of 1.070 and $1.096 \mathrm{~g} / \mathrm{ml}$ densities were collected and washed twice with ice-cold DMEM/F12-0.1\% BSA medium. The collected Leydig cells were seeded in a NUNC 24-multiwell plate (Nunc, Roskilde, Denmark). The cells were pre-incubated in DMEM/F12-0.1\% BSA at $34^{\circ} \mathrm{C}$ in a humidified atmosphere of $5 \% \mathrm{CO}_{2} / 95 \%$ air. The Leydig cells were incubated for $24 \mathrm{~h}$ with one of the following treatments: $0.01 \mathrm{IU} / \mathrm{ml}$ of hCG (Sigma), 1, 10 and $100 \mathrm{nM}$ recombinant chemerin (2324CM-025, R\&D Systems, Minneapolis, MN, USA), or the combination of hCG and chemerin or culture media only. The conditioned media were collected for testosterone measurement. The cells were lysed for QPCR analysis or western blot analysis. A batch of cells loaded in parallel were prepared and the cell purity was determined by

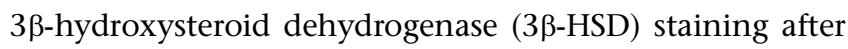
$24 \mathrm{~h}$ pre-incubation.

\section{Western blot}

The cells were lysed by M-PER Mammalian Protein Extraction Reagent (Pierce, Thermo Scientific, Rockford, IL, USA). After 10 min incubation on ice, the cell lysates were centrifuged and the supernatants were assayed for protein concentration using a BCA Protein Assay Kit (Pierce, Thermo Scientific). The samples containing $30 \mu \mathrm{g}$ total protein were subjected to electrophoresis on NuPage $4-12 \%$ Bis-Tris gradient gels (Invitrogen). The gels were blotted onto the PVDF membranes (PerkinElmer Life Sciences, Boston, MA, USA). Western blot was conducted

Published by Bioscientifica Ltd.

Downloaded from Bioscientifica.com at $04 / 26 / 2023$ 12:31:38AM via free access 
using rabbit MAB to 33-HSD (1:5000, ab150384, Abcam), rabbit MAB to phospho-p44/42 MAPK (Erk1/2) (1:2000, \#4370, Cell signaling, Boston, MA, USA), rabbit MAB to p44/42 MAPK (Erk1/2) (1:1000, \#4695, Cell signaling), followed by an incubation with HRP-conjugated goat anti-rabbit IgG (1:8000, ab136817, Abcam). Specific bands were visualised with a chemiluminescent reagent (Western-lightening Plus, PerkinElmer Life Sciences). The blots were then washed in PBS and were re-probed with rabbit anti-actin serum (1:5000, Sigma). PageRuler Prestained Protein Ladder 10-170K (Pierce, Thermo Scientific) was loaded in a well next to the samples, fractionated on the same gel and transferred to the membrane. Sizes of the specific bands were determined with the prestained protein ladder band profile. Specific bands of a size consistent with that of the target proteins were detected by western blotting for 3 $\beta$-HSD (42 kDa), phospho-p44/42 MAPK (44, $42 \mathrm{kDa})$ and p44/42 MAPK (42, $44 \mathrm{kDa})$.

\section{Testosterone measurements by RIA}

Testosterone levels in the conditioned media were measured using commercial Iodine $\left[{ }^{125} \mathrm{I}\right]$ RIA Kits (Lareneen, Guangzhou, China). The sensitivity of the testosterone RIA assay was $20 \mathrm{ng} / \mathrm{ml}$. The intra-assay error and inter-assay error were $<10$ and $15 \%$ respectively.

\section{Statistical analysis}

All data are expressed as mean \pm s.E.M., and statistical significance was assessed by either one-way ANOVA followed by Fisher's least significant difference test for post-hoc comparisons or Student's t-test (GraphPad Prism, San Diego, CA, USA). $P<0.05$ was considered statistically significant.

\section{Results}

\section{The expression and localisation of chemerin and its receptors Cmklr1, Gpr1 and Ccrl2 in rat and human testes}

Although chemerin RNA levels were relatively low in the adult testis (Fig. 1) compared with liver, epididymal fat, chemerin protein was detected in the cytoplasm of the interstitial Leydig cells and to a lesser extent in the spermatogonia and spermatocytes inside the seminiferous tubules (Fig. 2A). Cmklr1 and Gpr1 RNA were expressed at significantly higher levels in the testes compared with other tissues of the male reproductive system, as well as liver and epididymal fat (Fig. 1). Consistent with the high gene
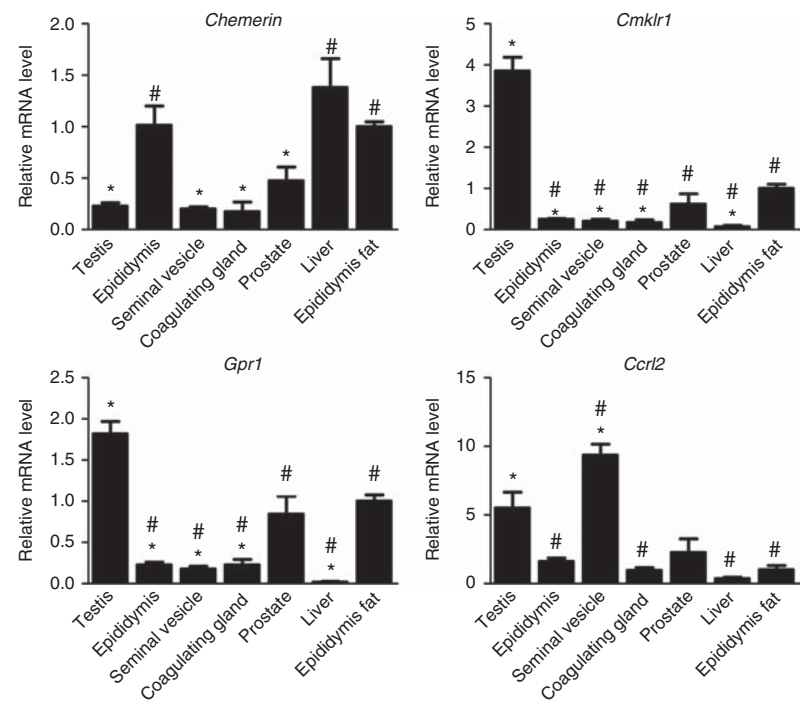

Figure 1

Expression of chemerin and its receptors in male reproductive tissues. Analysis of relative gene expression of chemerin, $C m k / r 1, G p r 1$ and $\mathrm{Ccrl} 2$ by QPCR in adult rat male reproductive tissues including testis, epididymis, seminal vesicle, coagulating gland and prostate and using liver and epididymal adipose tissue as controls; $\beta$-actin served as the reference gene; $n=5-8$; all data were expressed as mean \pm s.E.M. ${ }^{*} P<0.05$ compared with epididymis fat, ${ }^{\#} P<0.05$ compared with testis for one-way ANOVA followed by Fisher's least significant difference test.

expression in the testis, antibodies against CMKLR1 and GPR1 stained interstitial Leydig cells in rat and human testes (Fig. 2). Ccrl2 RNA was expressed at relatively higher levels in the testes and seminal vesicles compared with other male reproductive tissues, or liver and epididymal fat (Fig. 1), although there was only weak to negligible CCRL2 immunostaining in human and rat testes (Fig. 2).

The expression of chemerin and its receptors Cmklr1, Gpr1 and $\mathrm{Ccr} / 2$ in rat testes is developmentally regulated and highly expressed in Leydig cells

We next asked whether the expression of chemerin and its receptors in the testes changed over time during postnatal development. Testicular chemerin expression consistently decreased over time from the neonatal period to adulthood (Fig. 3). In contrast, expression of Cmklr1, Gpr1 and Ccrl2 increased over this period-Cmklr1 and Gpr1 at the transitional period from pre-adolescence (day 15) to peripuberty (day 30) and Ccrl2 at day 60 (Fig. 3). The primary Leydig cells were isolated and the gene expression of chemerin and its receptors Cmklr1, Gpr1 and Ccrl2 was compared with that of whole testis. Leydig cells in general showed a higher expression level of chemerin and its receptors Cmklr1 and Gpr1 (Fig. 4). Thus, in male

Published by Bioscientifica Ltd. 

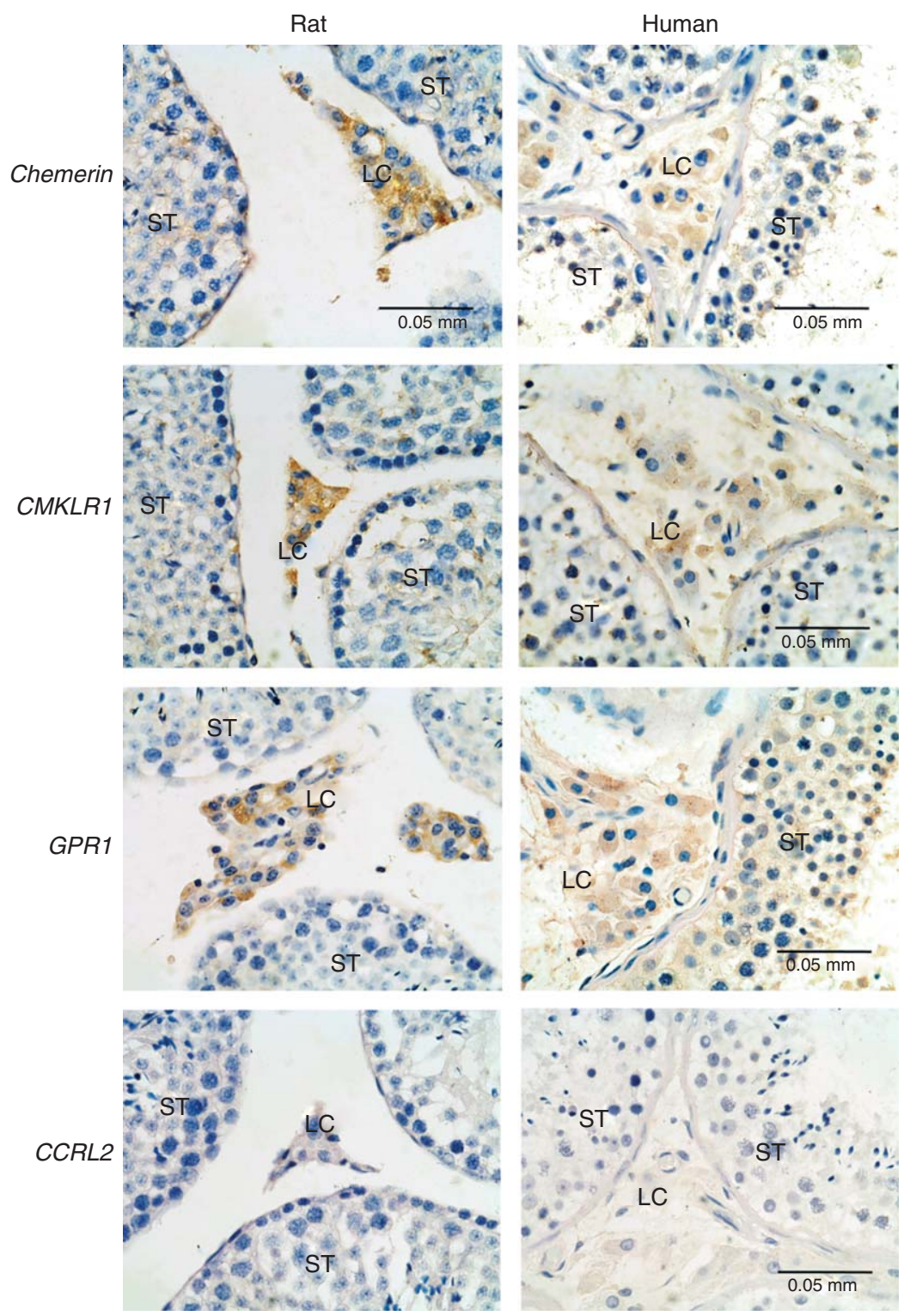

Figure 2

Immunolocalisation of chemerin and its receptors in rat and human testes sections. Chemerin and its receptors CMKLR1 and GRP1 were localised to interstitial Leydig cells and to a lesser extent in the spermatogonia and spermatocytes inside the seminiferous tubules. Parallel sections with

reproductive tissues, expression of chemerin and its receptors is developmentally regulated and is cell-type selective.

\section{Chemerin suppresses testicular steroidogenesis accompanied by the inhibition of both $3 \beta-H S D$ expression and p44/42 MAPK (Erk1/2) phosphorylation}

The high expression of chemerin and its receptors in Leydig cells prompted us to explore the possible effects of chemerin on steroidogenesis by a direct in vitro study primary antibody replaced by non-immune serum serve as control (result not shown); scale bars, $0.05 \mathrm{~mm}$; LC, interstitial Leydig cells; ST, seminiferous tubule; similar results were obtained with rats and human $(n=3)$.

of the Leydig cells. In cultured primary Leydig cells, $24 \mathrm{~h}$ incubation with hCG induced considerable secretion of testosterone (Fig. 5A), which was significantly suppressed by cotreatment with chemerin at doses of 1 , 10 and $100 \mathrm{nM}$ (Fig. 5A). HCG stimulation resulted in the upregulation of steroidogenic key factors including $H s d 3 b$ (Fig. 5B), Star, Cyp11a1 and Hsd17b1 (data not shown). The suppressive effect of chemerin on hCG-stimulated testosterone production was accompanied by the suppression of hCG-stimulated gene and 

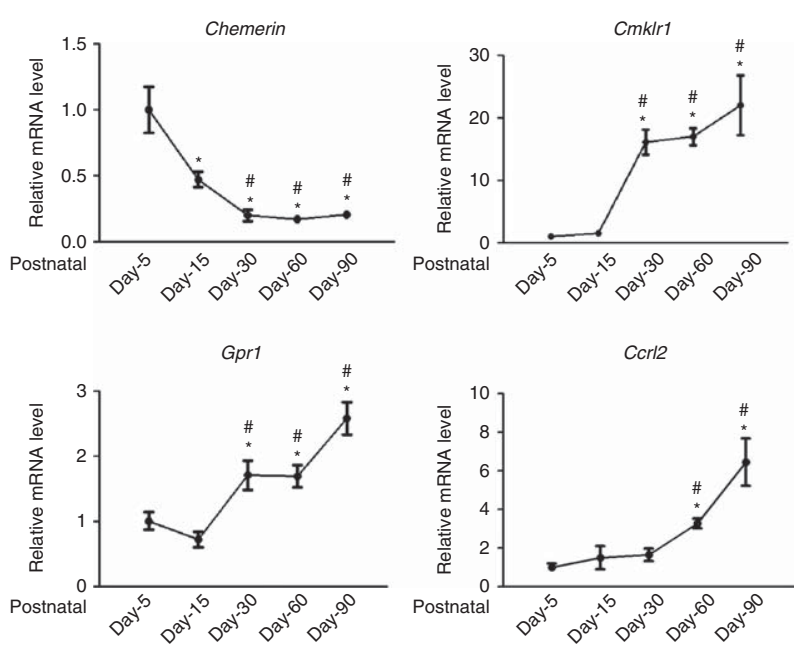

Figure 3

The relative gene expression of chemerin and its receptors during postnatal development in testes from 5-, 15-, 30-, 60- and 90-day old rats. $n=4-5$, L19 ribosomal protein mRNA served as the reference gene; all data were expressed as mean \pm s.E.M.; ${ }^{*} P<0.05$ compared with day- 5 and ${ }^{\#} P<0.05$ compared with day- 15 for one-way ANOVA followed by Fisher's least significant difference test.

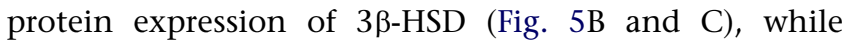
leaving expression of Star, Cyp11a1 and Hsd17b1 unaffected (data not shown). Chemerin alone had no effect on basal testosterone secretion or 3 $\beta$-HSD expression (Fig. 5A, B and C). Also cotreatment of chemerin inhibited the hCG-activated p44/42 MAPK (Erk1/2) pathway, while chemerin alone showed no effect on the phosphorylation of p44/42 MAPK (Fig. 6).

\section{Discussion}

At least two noteworthy observations have surfaced from our investigations on the role of chemerin and its receptors in reproduction. First, in male reproductive tissue, expression of chemerin and its receptors is highly regulated by developmental factors and is cell-type selective, with GPR1, CMKLR1 and chemerin protein highly expressed in the testes, specifically Leydig cells. Second, chemerin suppresses hCG-induced testosterone secretion by primary Leydig cells at 1, 10 and $100 \mathrm{nM}$ and the suppression is accompanied by the inhibition of $3 \beta-H S D$ expression and p44/42 MAPK (Erk1/2) pathway. The estimated plasma and serum concentrations of chemerin were 3.0 and $4.4 \mathrm{nM}$ in human and 0.6 and $0.5 \mathrm{nM}$ in mouse respectively (Zabel et al. 2006). The effective doses in our study were within the physiological levels. Our study is the first to report the expression of the novel adipokine chemerin and its receptors CMKLR1 and GPR1 in human testis and to characterise its direct biological effects in mammalian male gonad.

Testicular expression of chemerin and its receptors appears to be under the regulation of developmental cues. The peri-puberty (30-day) period seems to be a switching point at which the chemerin level remains steady till adulthood while all the receptors increase after puberty. The importance of high chemerin level in neonatal rat remains to be explored while the increased receptors levels in post-puberty rat might suggest the growing importance of chemerin during adulthood. Actually our data indicated that chemerin suppressed the hCG-stimulated testosterone production, suggesting a regulatory role of chemerin in steroidogenesis of adult rats. Considering the expression of chemerin and its receptors in both the interstitium and seminiferous tubules, we cannot limit the biological functions of chemerin and its receptors to Leydig cells only. Its possible roles in spermatogenesis need more investigation. The decrease in chemerin gene expression level towards adulthood might be due to the presence of a feedback loop, i.e. the increase in the receptors (and therefore action) leading to a decrease in the ligand. The low protein level of CCRL2 in adulthood
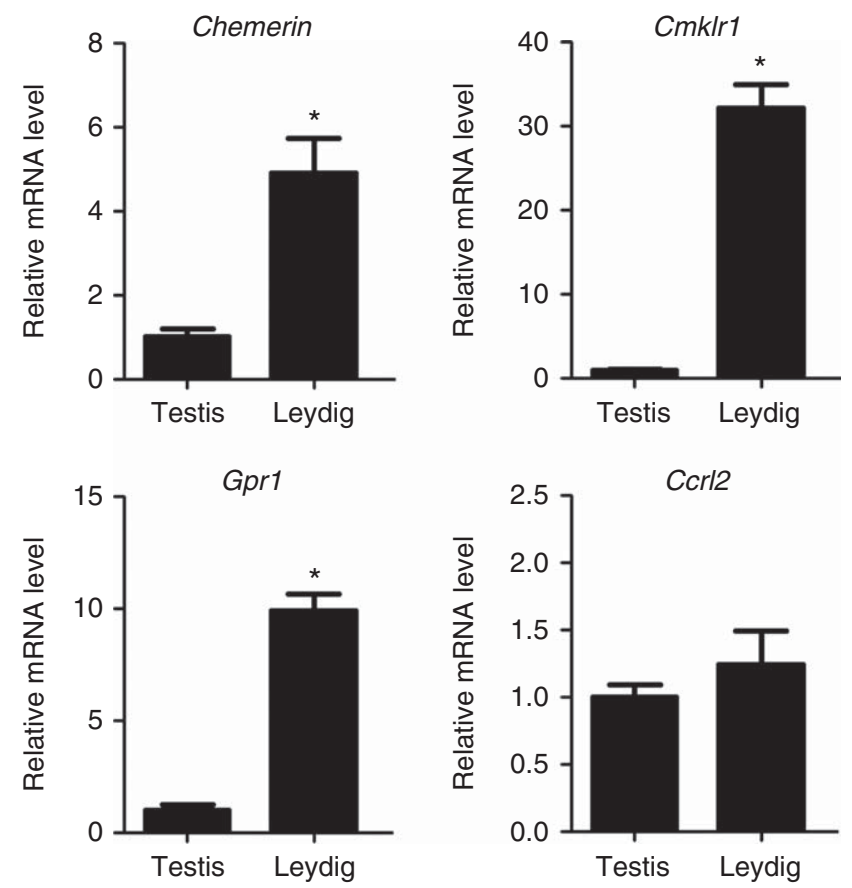

Figure 4

The relative gene expression of chemerin and its receptors in rat Leydig cells and whole testicular tissue. $\beta$-actin served as the reference gene; $n=4-5$, all data were expressed as mean \pm s.E.M.; ${ }^{*}<0.05$ for Student's $t$-test.

Published by Bioscientifica Ltd. 
A

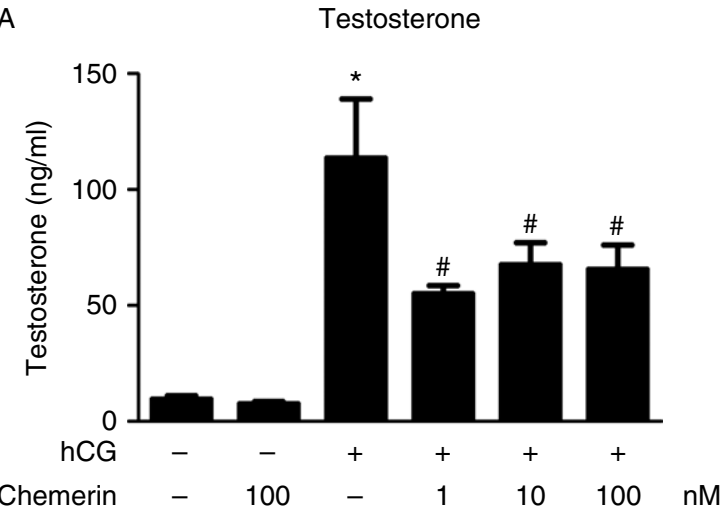

B

$H s d 3 b$

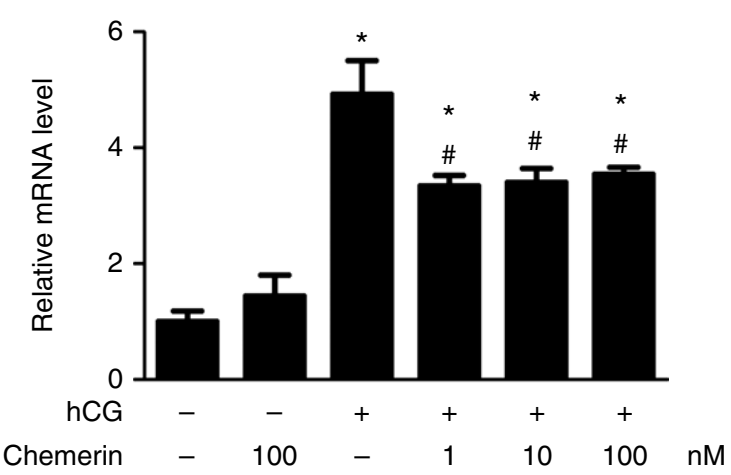

C

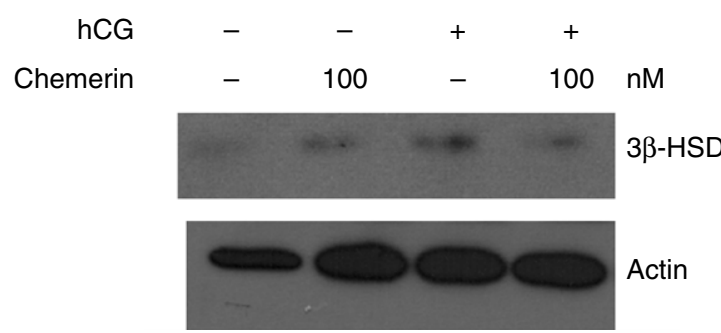

Figure 5

In vitro suppressive effect of chemerin on steroidogenesis in rat Leydig cells. In primary Leydig cell culture, chemerin showed no effect on basal testosterone production, but suppressed hCG-induced testosterone production (A), gene expression of $H s d 3 b$ (B) and protein expression of $3 \beta$-HSD (C). For (B), $\beta$-actin served as the reference gene; each experiment was repeated at least three times; all data were expressed as mean \pm S.E.M.; $* P<0.05$ compared with control group with no chemerin and no hCG treatment; ${ }^{\#} P<0.05$ compared with hCG alone treatment group for one-way ANOVA followed by Fisher's least significant difference test.

needs to be confirmed and any discrepancy with the increase in Ccrl2 gene expression towards adulthood requires further investigation.

Among all the three receptors of chemerin, CMKLR1 and GPR1 are more likely to mediate the binding of chemerin in Leydig cells and direct its following signaling pathways. There was only weak to negligible CCRL2 immunostaining found in either human or rat testes compared with the strong staining of CMKLR1 and GPR1. This could be due to a lower avidity of the anti-serum used compared with the antisera for other receptors or a lower level of the receptor protein. There was also no significant difference in the gene expression levels of Ccrl2 between isolated Leydig cells and the whole testis. This could be the result of a decrease in Ccrl2 gene expression in the Leydig cells or an increase in other cell types in the testis. The chemotactic activity of chemerin was mediated by binding to CMKLR1 (Barnea et al. 2008) and no biological actions of chemerin/GPR1 or chemerin/CCRL2 was reported except that binding of chemerin to CCRL2 might present chemerin to nearby cell displaying functional receptors (Monnier et al. 2012). The activation of chemerin/CMKLR1 pathway has been reported to result in the inhibition of the phosphorylation of MAPK ERK1/2 (Yoshimura \& Oppenheim 2011). In the primary Leydig cells of this study, the suppression of hCG-stimulated testosterone production by chemerin was accompanied by the inhibition of hCG-activated p44/42 MAPK (Erk1/2) pathway, suggesting that the activation of chemerin/CMKLR1 pathway is involved. The colocalisation of chemerin and its receptor CMKLR1 and GPR1 protein in Leydig cells of adult testes, the high expression level of chemerin in adjacent epididymis adipose tissue (Goralski et al. 2007) and the high circulating chemerin level reported (Zabel et al. 2006) suggest that the action of chemerin in testis could be autocrine, paracrine or endocrine mediating the binding of chemerin in Leydig cells and the subsequent signaling pathways. More investigations are needed to

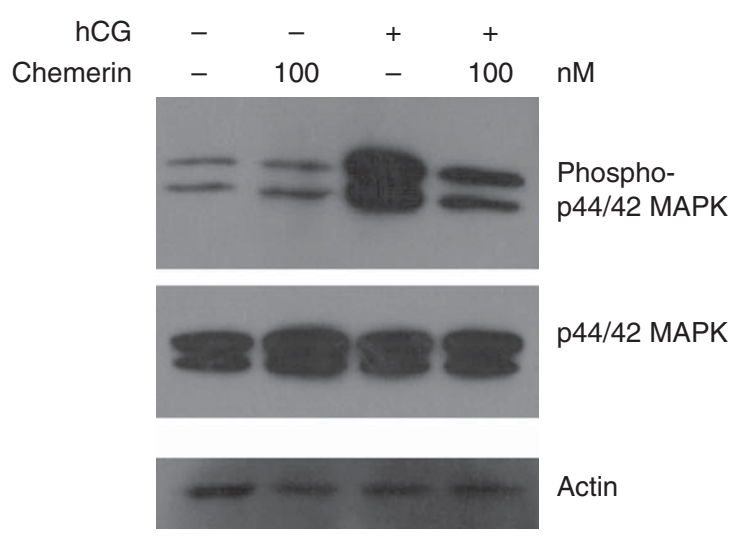

Figure 6

Chemerin inhibited the hCG-activated p44/42 MAPK (Erk1/2) pathway in primary Leydig cells. In primary Leydig cells, chemerin alone showed no effect on the phosphorylation of p44/42 MAPK. HCG treatment significantly activated the p44/42 MAPK (Erk1/2) pathway which was inhibited by chemerin cotreatment.

Published by Bioscientifica Ltd. 
identity which receptor(s) are responsible for the actions of chemerin in testis.

In summary, our data demonstrate the expression of chemerin in human and rat testes and provide the first evidence for the direct action of chemerin in testosterone secretion. This, together with the suppressive effects of chemerin on steroid hormone secretion from human (Reverchon et al. 2012) and rat (Wang et al. 2012) granulosa cells, suggesting that chemerin is a novel regulator of gonadal steroidogenesis.

\section{Declaration of interest}

The authors declare that there is no conflict of interest that could be perceived as prejudicing the impartiality of the research reported.

\section{Funding}

This work was supported by National Natural Science Foundation of China (grant number 81200434 to L L and grant number 31100850 to J V Z), grant from Shenzhen City of China (SW201110059 to J V Z), the National Major Basic Research Program of China (2013CB945503 to J V Z) and National Institutes of Health Grant (Al-079320 to B A Z).

\section{Author contribution statement}

$L L$ conceived and designed the experiments. $L L, P M, C H, Y L, Y Z, C G$ and $T X$ performed the experiments. $L L$ analysed the data. J V Z, B A Z and P-G R contributed reagents/materials/analysis tools. $L L$ and $B A Z$ wrote the paper.

\section{References}

Agarwal SK, Vogel K, Weitsman SR \& Magoffin DA 1999 Leptin antagonizes the insulin-like growth factor-I augmentation of steroidogenesis in granulosa and theca cells of the human ovary. Journal of Clinical Endocrinology and Metabolism 84 1072-1076. (doi:10.1210/jc.84.3.1072)

Barkan D, Jia H, Dantes A, Vardimon L, Amsterdam A \& Rubinstein M 1999 Leptin modulates the glucocorticoid-induced ovarian steroidogenesis. Endocrinology 140 1731-1738. (doi:10.1210/en.140.4.1731)

Barker G, Lim R, Rice GE \& Lappas M 2012 Increased chemerin concentrations in fetuses of obese mothers and correlation with maternal insulin sensitivity. Journal of Maternal-fetal \& Neonatal Medicine 25 2274-2280. (doi:10.3109/14767058.2012.686540)

Barnea G, Strapps W, Herrada G, Berman Y, Ong J, Kloss B, Axel R \& Lee KJ 2008 The genetic design of signaling cascades to record receptor activation. PNAS 105 64-69. (doi:10.1073/pnas.0710487105)

Bondue B, Wittamer V \& Parmentier M 2011 Chemerin and its receptors in leukocyte trafficking, inflammation and metabolism. Cytokine \& Growth Factor Reviews 22 331-338. (doi:10.1016/j.cytogfr.2011.11.004)

Bozaoglu K, Bolton K, McMillan J, Zimmet P, Jowett J, Collier G, Walder K $\&$ Segal D 2007 Chemerin is a novel adipokine associated with obesity and metabolic syndrome. Endocrinology 148 4687-4694. (doi:10.1210/ en.2007-0175)

Brannian JD, Zhao Y \& McElroy M 1999 Leptin inhibits gonadotrophinstimulated granulosa cell progesterone production by antagonizing insulin action. Human Reproduction 14 1445-1448. (doi:10.1093/ humrep/14.6.1445)
Duan DM, Niu JM, Lei Q, Lin XH \& Chen X 2011 Serum levels of the adipokine chemerin in preeclampsia. Journal of Perinatal Medicine $\mathbf{4 0}$ 121-127. (doi:10.1515/JPM.2011.127)

Ernst MC, Issa M, Goralski KB \& Sinal CJ 2010 Chemerin exacerbates glucose intolerance in mouse models of obesity and diabetes. Endocrinology 151 1998-2007. (doi:10.1210/en.2009-1098)

Garces MF, Sanchez E, Acosta BJ, Angel E, Ruiz AI, Rubio-Romero JA, Dieguez C, Nogueiras R \& Caminos JE 2012 Expression and regulation of chemerin during rat pregnancy. Placenta 33 373-378. (doi:10.1016/ j.placenta.2012.02.007)

Goralski KB, McCarthy TC, Hanniman EA, Zabel BA, Butcher EC, Parlee SD, Muruganandan S \& Sinal CJ 2007 Chemerin, a novel adipokine that regulates adipogenesis and adipocyte metabolism. Journal of Biological Chemistry 282 28175-28188. (doi:10.1074/jbc.M700793200)

Hausman GJ \& Barb CR 2010 Adipose tissue and the reproductive axis: biological aspects. Endocrine Development 19 31-44. (doi:10.1159/ 000316895)

Kitawaki J, Kusuki I, Koshiba H, Tsukamoto K \& Honjo H 1999 Leptin directly stimulates aromatase activity in human luteinized granulosa cells. Molecular Human Reproduction 5 708-713. (doi:10.1093/molehr/5.8.708)

Li L \& Wong CK 2008 Effects of dexamethasone and dibutyryl cAMP on stanniocalcin-1 mRNA expression in rat primary Sertoli and Leydig cells. Molecular and Cellular Endocrinology 283 96-103. (doi:10.1016/ j.mce.2007.11.028)

Livak KJ \& Schmittgen TD 2001 Analysis of relative gene expression data using real-time quantitative PCR and the $2(-$ Delta Delta $C(T))$ method. Methods 25 402-408. (doi:10.1006/meth.2001.1262)

Meder W, Wendland M, Busmann A, Kutzleb C, Spodsberg N, John H, Richter R, Schleuder D, Meyer M \& Forssmann WG 2003 Characterization of human circulating TIG2 as a ligand for the orphan receptor ChemR23. FEBS Letters 555 495-499. (doi:10.1016/S00145793(03)01312-7)

Monnier J, Lewen S, O’Hara E, Huang K, Tu H, Butcher EC \& Zabel BA 2012 Expression, regulation, and function of atypical chemerin receptor CCRL2 on endothelial cells. Journal of Immunology 189 956-967. (doi:10.4049/jimmunol.1102871)

Nogueiras R, Barreiro ML, Caminos JE, Gaytan F, Suominen JS, Navarro VM, Casanueva FF, Aguilar E, Toppari J, Dieguez C et al. 2004 Novel expression of resistin in rat testis: functional role and regulation by nutritional status and hormonal factors. Journal of Cell Science $\mathbf{1 1 7}$ 3247-3257. (doi:10.1242/jcs.01196)

Parlee SD, Ernst MC, Muruganandan S, Sinal CJ \& Goralski KB 2010 Serum chemerin levels vary with time of day and are modified by obesity and tumor necrosis factor- $\{\alpha\}$. Endocrinology 151 2590-2602. (doi:10.1210/ en.2009-0794)

Poulos SP, Hausman DB \& Hausman GJ 2010 The development and endocrine functions of adipose tissue. Molecular and Cellular Endocrinology 323 20-34. (doi:10.1016/j.mce.2009.12.011)

Reverchon M, Cornuau M, Rame C, Guerif F, Royere D \& Dupont J 2012 Chemerin inhibits IGF-1-induced progesterone and estradiol secretion in human granulosa cells. Human Reproduction 27 1790-1800. (doi:10.1093/humrep/des089)

Spicer LJ \& Francisco CC 1998 Adipose obese gene product, leptin, inhibits bovine ovarian thecal cell steroidogenesis. Biology of Reproduction $\mathbf{5 8}$ 207-212. (doi:10.1095/biolreprod58.1.207)

Stepan H, Philipp A, Roth I, Kralisch S, Jank A, Schaarschmidt W, Lossner U, Kratzsch J, Bluher M, Stumvoll M et al. 2011 Serum levels of the adipokine chemerin are increased in preeclampsia during and 6 months after pregnancy. Regulatory Peptides 168 69-72. (doi:10.1016/ j.regpep.2011.03.005)

Takahashi M, Okimura Y, Iguchi G, Nishizawa H, Yamamoto M, Suda K, Kitazawa R, Fujimoto W, Takahashi K, Zolotaryov FN et al. 2011 Chemerin regulates $\beta$-cell function in mice. Scientific Reports $\mathbf{1} 123$ (doi:10.1038/srep00123)

Tan BK, Chen J, Farhatullah S, Adya R, Kaur J, Heutling D, Lewandowski KC, O'Hare JP, Lehnert H \& Randeva HS 2009 Insulin and metformin regulate 
circulating and adipose tissue chemerin. Diabetes 58 1971-1977. (doi:10.2337/db08-1528)

Tena-Sempere M, Pinilla L, Gonzalez LC, Dieguez C, Casanueva FF \& Aguilar E 1999 Leptin inhibits testosterone secretion from adult rat testis in vitro. Journal of Endocrinology 161 211-218. (doi:10.1677/joe.0. 1610211)

Tersigni C, Di Nicuolo F, D’Ippolito S, Veglia M, Castellucci M \& Di Simone N 2011 Adipokines: new emerging roles in fertility and reproduction. Obstetrical \& Gynecological Survey 66 47-63. (doi:10.1097/OGX. ob013e318217b0a4)

Wang Q, Kim JY, Xue K, Liu JY, Leader A \& Tsang BK 2012 Chemerin, a novel regulator of follicular steroidogenesis and its potential involvement in polycystic ovarian syndrome. Endocrinology 153 5600-5611. (doi:10.1210/en.2012-1424)

Wittamer V, Franssen JD, Vulcano M, Mirjolet JF, Le Poul E, Migeotte I, Brezillon S, Tyldesley R, Blanpain C, Detheux M et al. 2003 Specific recruitment of antigen-presenting cells by chemerin, a novel processed ligand from human inflammatory fluids. Journal of Experimental Medicine 198 977-985. (doi:10.1084/jem.20030382)

Yoshimura T \& Oppenheim JJ 2011 Chemokine-like receptor 1 (CMKLR1) and chemokine (C-C motif) receptor-like 2 (CCRL2); two multifunctional receptors with unusual properties. Experimental Cell Research 317 674-684. (doi:10.1016/j.yexcr. 2010.10.023)
Zabel BA, Allen SJ, Kulig P, Allen JA, Cichy J, Handel TM \& Butcher EC $2005 a$ Chemerin activation by serine proteases of the coagulation, fibrinolytic, and inflammatory cascades. Journal of Biological Chemistry 280 34661-34666. (doi:10.1074/jbc.M504868200)

Zabel BA, Silverio AM \& Butcher EC 2005 $b$ Chemokine-like receptor 1 expression and chemerin-directed chemotaxis distinguish plasmacytoid from myeloid dendritic cells in human blood. Journal of Immunology 174 244-251.

Zabel BA, Zuniga L, Ohyama T, Allen SJ, Cichy J, Handel TM \& Butcher EC 2006 Chemoattractants, extracellular proteases, and the integrated host defense response. Experimental Hematology 34 1021-1032. (doi:10.1016/j.exphem.2006.05.003)

Zabel BA, Nakae S, Zuniga L, Kim JY, Ohyama T, Alt C, Pan J, Suto H, Soler D, Allen SJ et al. 2008 Mast cell-expressed orphan receptor CCRL2 binds chemerin and is required for optimal induction of IgE-mediated passive cutaneous anaphylaxis. Journal of Experimental Medicine 205 2207-2220. (doi:10.1084/jem.20080300)

Zachow RJ, Weitsman SR \& Magoffin DA 1999 Leptin impairs the synergistic stimulation by transforming growth factor- $\beta$ of follicle-stimulating hormone-dependent aromatase activity and messenger ribonucleic acid expression in rat ovarian granulosa cells. Biology of Reproduction 61 1104-1109. (doi:10.1095/ biolreprod61.4.1104)

Received in final form 28 November 2013

Accepted 3 December 2013

Accepted Preprint published online 3 December 2013
(C) 2014 Society for Endocrinology Printed in Great Britain 